\title{
PEBA Regimen
}

National Cancer Institute

\section{Source}

National Cancer Institute. PEBA Regimen. NCI Thesaurus. Code C67515.

A regimen consisting of cisplatin, etoposide, bleomycin and dactinomycin (Actinomycin-

D), used for the treatment of poor-prognosis metastatic gestational trophoblastic tumors (GTT). 